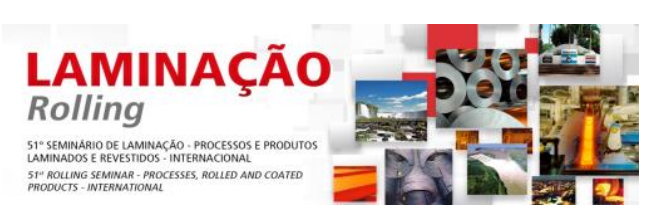

\title{
MASTERING THE FUTURE WITH X-ROLL 2.0 - COLD ROLLING TECHNOLOGY OF THE NEXT GENERATION*
}

\author{
Jürgen Schanderl ${ }^{1}$ \\ Rüdiger Holz ${ }^{2}$ \\ Karl Hoen ${ }^{3}$
}

\begin{abstract}
Cold rolling mills by SMS Siemag are well known for their reliability and long-life cycle. They are an investment in the future. Nowadays mill owners are under considerable competitive pressure and are asked to organize production in a more and more efficient and flexible way. Doing so, a number of elevating screws have to be turned. These are: cutting of operation costs, especially by more efficient equipment and processes as well as transition to more process flexibility to fulfil future product requirements. To support owners in their effort, SMS Siemag offers convincing solutions in cold rolling technology under the brand X-Roll 2.0. Examples to be presented are: Sieflex ${ }^{\circledR}-\mathrm{HT}$ drive technology; Redesigned DS system; New reel design: Twin Reel; Emulsion compact unit ECU Compact; $\mathrm{TRC}^{\circledR}$ threading assistance system; ECOMode and Energy ADVISOR monitoring system.

Keywords: X-Roll ${ }^{\circledR}$; Sieflex ${ }^{\circledR}-\mathrm{HT}$; Emulsion Compact Unit (ECU); Twin reel; TRC ${ }^{\circledR}$; ECO Mode; Energy advisor.
\end{abstract}

1 Mechanical Engineer, General Manager Technical Sales Reversing Cold Rolling Mills and Skin Pass Mills, Flat Rolling Plants Division, SMS Siemag AG, Hilchenbach, Germany.

2 Mechanical Engineer, Executive Vice President, Flat Rolling Plants Division, SMS Siemag, Hilchenbach, Germany.

3 Mechanical Engineer, General Manager Innovation Management Technological Commissioning, Patent, Flat Rolling Plants Division, SMS Siemag AG, Hilchenbach, Germany.

* Technical contribution to the 51st Rolling Seminar - Processes, Rolled and Coated Products, October $28^{\text {th }}$ to $31^{\text {st }}, 2014$, Foz do Iguaçu, PR, Brazil. 


\section{INTRODUCTION}

The well-known and well-proven rolling technology of SMS Siemag is established under the X-Rol ${ }^{\circledR}$ label. For further support of mill owners, who are under huge competitive pressure, SMS Siemag has developed a bunch of new technological solutions and introduces them under the brand $X-$ Ro $^{\circledR}{ }^{\circledR} 2.0$ to the market. The new XRoll $^{\circledR}$ generation features innovations, ensuring an even more flexible and economically efficient plant operation as well as meeting ecological requirements, which become more and more challenging nowadays.

The technical solutions of the second X-Rol ${ }^{\circledR}$ generation offer numerous advantages not only for the design of greenfield plants but also for upgrades and modernizations of existing ones. The examples to be discussed in this paper are:

- Sieflex ${ }^{\circledR} H T$ drive spindle for transmission of high rolling torques with the same or even smaller work roll diameter (Compact Mill)

- More cost-efficient strip blow-off system through further reduced compressed air consumption

- Twin Reel: the compact reel concept for highest requirements of a continuous tandem mill

- ECU - The space and energy-saving compact emulsion system

- $\mathrm{TRC}^{\circledR}$ - Thread and tail-out assistant for fast start of rolling and lower offgauge lengths

- ECO Mode and Energy Advisor create the required transparency for operating the mill and the plant more efficiently

\section{SIEFLEX ${ }^{\circledR}$-HT DRIVE SPINDLE FOR TRANSMISSION OF HIGH ROLLING TORQUE}

\subsection{Initial Situation}

In cold rolling mills the preferred type of drive is the work roll drive (Figure 1). It has the highest process stability and is normally less expensive than intermediate roll or backup roll drives. However, there are constraints for the work roll drive because for thinner work rolls the respectively thinner roll necks and drive spindles are often limiting the capability of transmitting the required rolling torque.

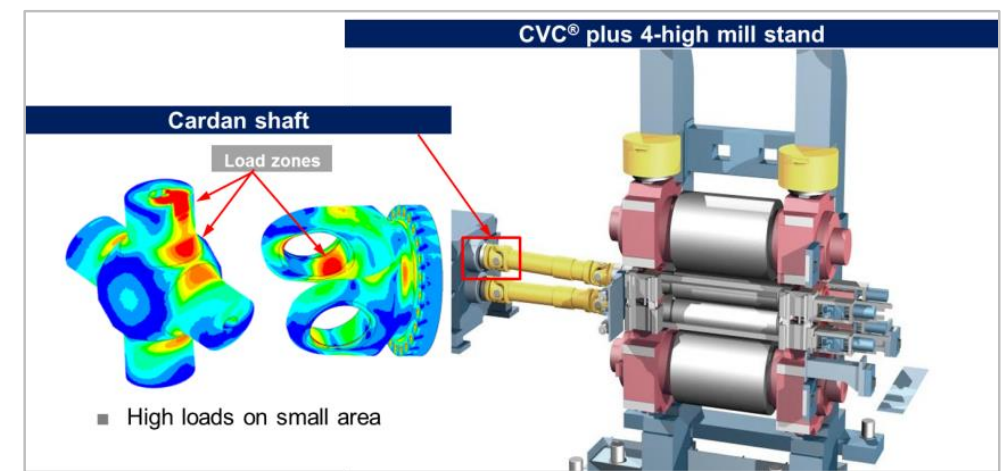

Figure 1: $\mathrm{CVC}^{\circledR}$ plus 4-high mill stand with driven work rolls and load distribution on the cardan shafts

* Technical contribution to the 51st Rolling Seminar - Processes, Rolled and Coated Products, October $28^{\text {th }}$ to $31^{\text {st }}, 2014$, Foz do Iguaçu, PR, Brazil. 


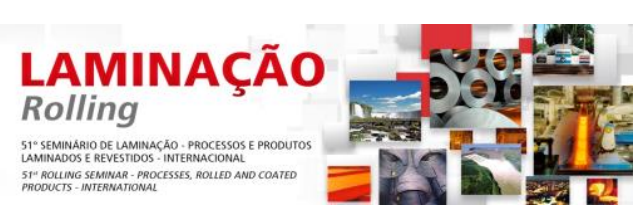

approx. 60 percent. However, there is still an significant amount of compressed air required for SMS Siemag's wearless sealing of the work roll barrel in the last stand. So the main target of the further development of the X-Roll ${ }^{\circledR}$ DS system was to reduce the remaining compressed air consumption.

\subsection{Solution}

The productive efficiency of the SMS Siemag DS systems is characterized by well aimed blow-off and sucking areas (Figure 3).

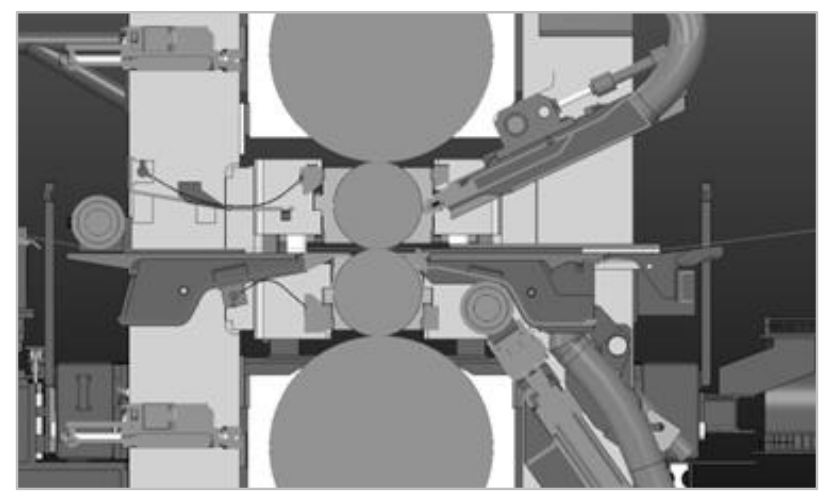

Figure 3: Basic design of an exit-side DS system with elements for blowing off an sealing.

The wearless and contactless sealing of the roll barrel is achieved by a high-speed air flow, generated with the aid of the Coanda effect of the so called "COANDA nozzle". In order to cut down the amount of compressed air, it was simulated with CFD (Figure 4) and the contour was optimized.

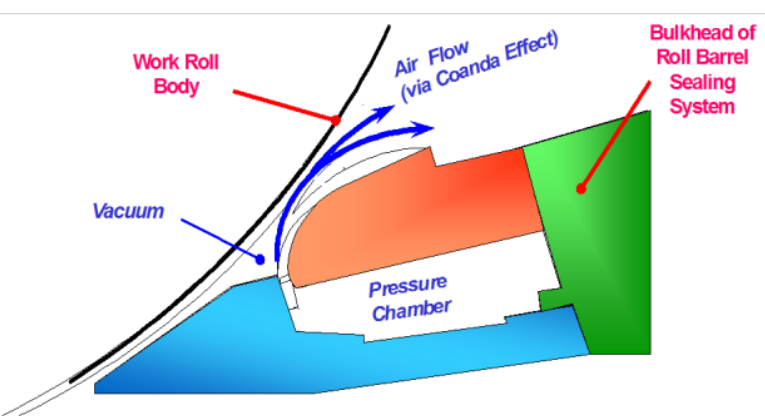

Figure 4: Functionality of the COANDA nozzle as contactless sealing of the work roll barrel

\subsection{Results}

The modified contour ensures an improved flow, deflecting the drop-laden air and providing reliable sealing towards the strip. In that way a higher drying effect can be achieved on the strip. Furthermore, the nozzles in the edge area can be switched off. With the modification of the nozzle contour it is now possible to reduce the consumption of compressed air by more than 50 percent, which comes along with appropriate operation cost savings.

* Technical contribution to the 51st Rolling Seminar - Processes, Rolled and Coated Products, October $28^{\text {th }}$ to $31^{\text {st }}, 2014$, Foz do Iguaçu, PR, Brazil. 


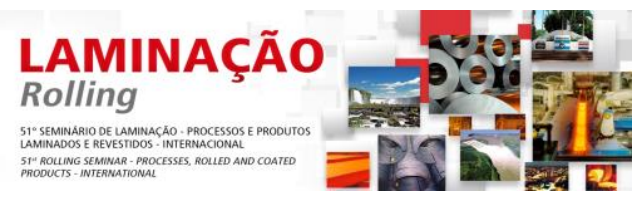

\section{TWIN REEL: THE COMPACT REEL CONCEPT FOR HIGHEST REQUIREMENTS OF A CONTINUOUS TANDEM MILL}

\subsection{Initial Situation}

SMS Siemag offers two proven reel concepts for the continuous exit section of tandem cold mills: double reel (Figure 5) and carousel reel (Figure 6). Both reel concepts ensure high productivity and very accurate winding results. However each has specific advantages making it preferable for different production scenarios.
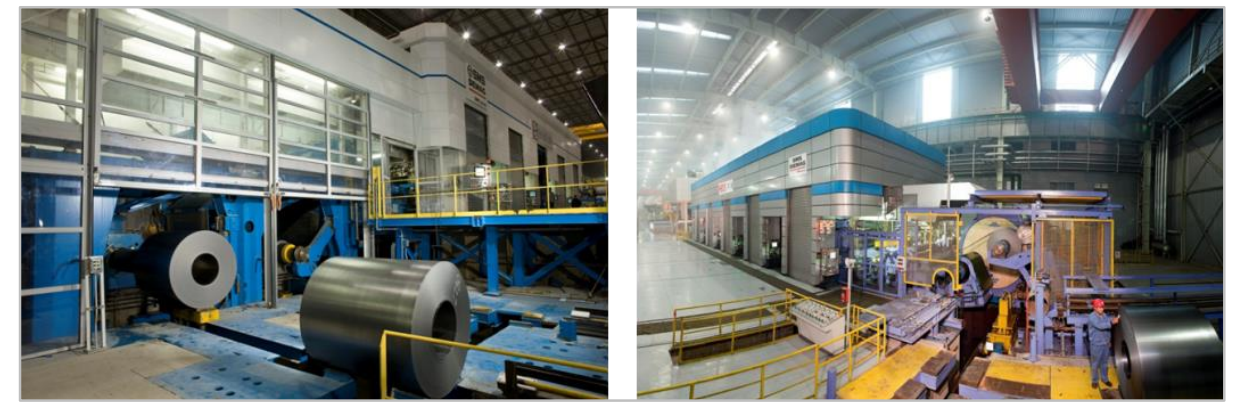

Figures 5 and 6: Double reel (I) and carousel reel $(r)$ are both proven solutions for the exit section of tandem cold mills esuring continuous operation

For the double reel, two individual reels are arranged in a row and therefore the required space is bigger than for the carousel reel. The double reel is designed for high capacities and high strength material. Coiling under high strip tensions is possible right from the beginning. For the transportation of the finished coils two coil cars are needed. The distance between the last mill stand and the two mandrels is different. As different is the way the strip head end has to pass safely before being coiled. This might increase the risk for strip damages, especially in case of ultra-thin strip.

The carousel reel is compactly designed with its two mandrels being arranged on a rotor. The mandrel position for the initial windings is always the same. Also there is only one coil take off position and therefore only one coil car is needed. In the "start of winding position", the mandrel is not stabilized by a support bearing, with the result that high strip tensions cannot be applied as long as the mandrel has reached the winding and take off position. After pivoting to this position, it is hold by a support bearing. Only now high strip tensions can be applied for the winding. This situation has effects on the stability of the first windings. However for thin and ultra-thin strips the carousel reel concept is beneficial.

\subsection{Solution}

SMS Siemag asked itself how an alternative reel design for the continuous exit section of tandem mills could look like. Result of this process is the Twin Reel. It combines the advantages of both conventional solutions and even outclasses them by its intelligent, very robust and economic design. It opens up the opportunity of coiling with remarkably higher strip tensions right from the beginning and allows constant coiling quality for all products required, from soft to high-strength and very thin strips.

\footnotetext{
* Technical contribution to the 51st Rolling Seminar - Processes, Rolled and Coated Products, October $28^{\text {th }}$ to $31^{\text {st }}, 2014$, Foz do Iguaçu, PR, Brazil.
} 


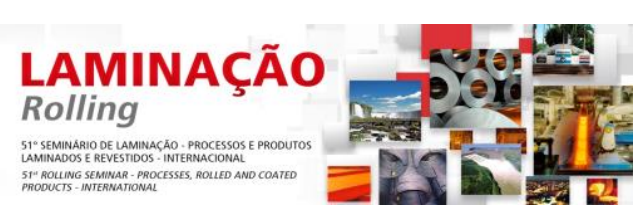

Double and carousel reel have in common that the finished coils are removed on the operator side. The new Twin Reel breaks with this principle. Both reel drives are opposed to each other, one is arranged on the operator and one on the drive side. In between the coiling takes place. Figure 7 shows the entire Twin Reel configuration. The reel mandrels are of proven design and are supported in every position on both sides. The first windings of the new coil are coiled with the mandrel in the upper position. It will be finished in the lower position and transported away inline to the mill. All this simplified the design compared to the carousel reel.

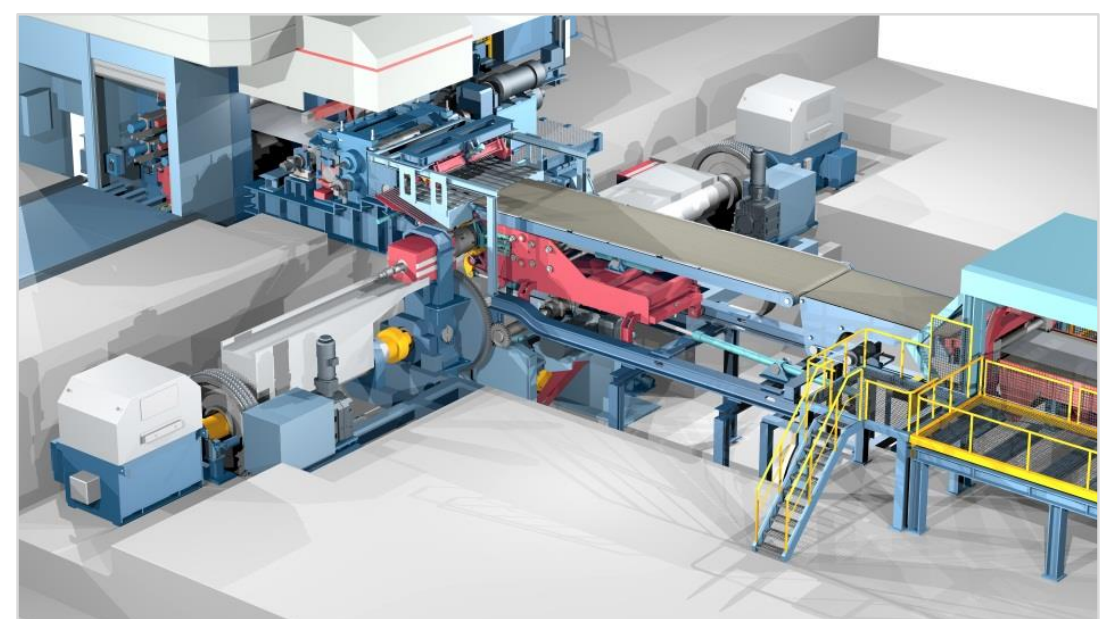

Figure 7: Concept presentation of the new continuous exit section by SMS Siemag with the Twin Reel

\subsection{Results}

The Twin Reel is designed for coils of up to 60 tons weight, so called "jumbo coils". The finish-rolled strip is coiled from the start at high strip tension, thus leading to a stable coil eye and allowing higher accuracy in coiling, even for wide strips. The strip tension level as a whole is higher, which is an advantage for rolling high-strength grades.

Even very thin strips are coiled safely because the initial coiling distance is very short. Compared to similar exit configuration as in figure 7 but with carousel reel for the Twin Reel the coiling distance is even smaller. Belt wrapper and spool operation can certainly be integrated into the new reel concept as well as the "Rotary Inspect" inspection station. The coil transport in direction of the strip flow is significantly simplified and more cost-efficient.

The complete accessibility of the exit area with gearbox, reel mandrels and belt wrappers is improved by transporting the coils under mill floor level. The design of the foundation is very simple and clear.

The new Twin Reel is not only suitable for new plants but can also be installed in existing tandem mills, for example along with the revamp from the discontinuous to continuous operation.

\section{ECU - THE SPACE AND ENERGY-SAVING COMPACT EMULSION SYSTEM}

\subsection{Initial Situation}

The main components of an emulsion system are the pipelines to the rolling mill, fluid tanks, cleaning equipment, stirrer, cooling and heating equipment, pumps and

* Technical contribution to the 51st Rolling Seminar - Processes, Rolled and Coated Products, October $28^{\text {th }}$ to $31^{\text {st }}, 2014$, Foz do Iguaçu, PR, Brazil. 


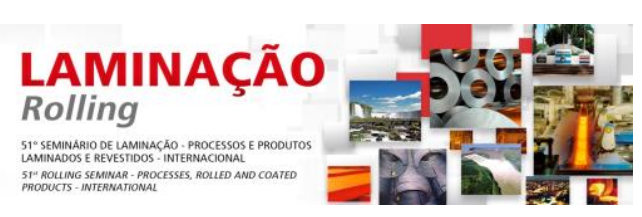

pipework (Figure 8). With the conventional design, this requires a floor space of approx. 300 square meters.

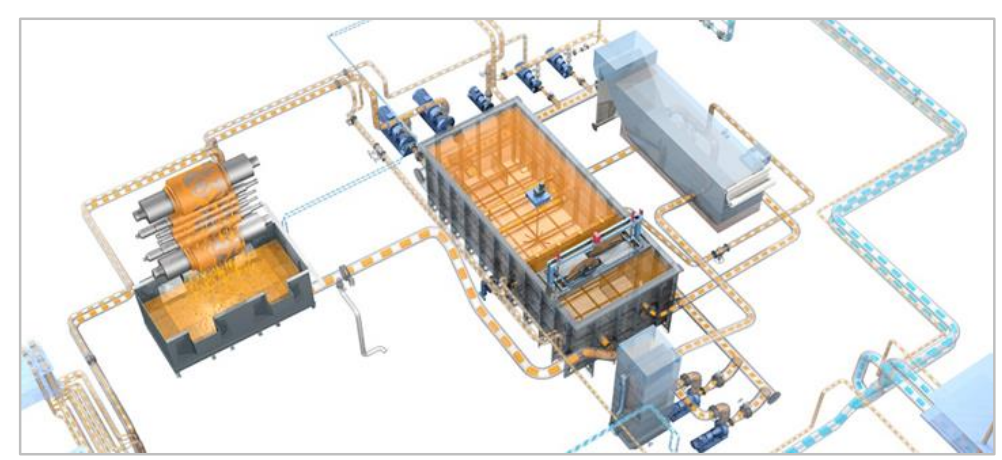

Figure 8: Typical arrangement of a conventional emulsion plant

For further improve the well established conventional emulsion system SMS Siemag launched the Emulsion Compact Unit (ECU).

\subsection{Solution}

The ECU compact emulsion system is characterized by its extremely space-saving design. The components of the emulsion plant are no longer arranged separately and linked with each other by long piping systems. They are arranged compactly in a unit. The devices are arranged on two levels. The pumps and tanks are installed on the floor plate while the heat exchanger, filters and magnetic separator are located on the tanks (Figure 9).

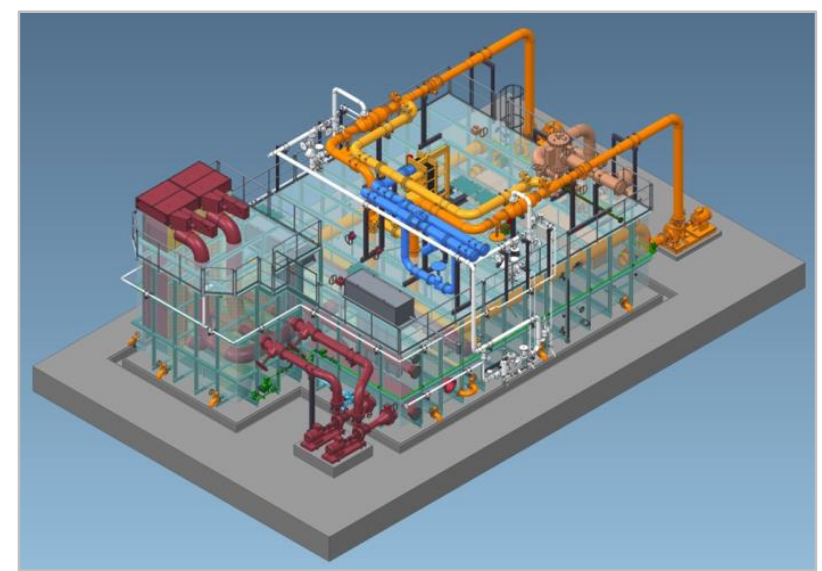

Figure 9: SMS Siemag's new economical ECU emulsion system

The emulsion heated up in the rolling mill is cleverly used to control the temperature of the oil and water tanks. Therefor and together with an intelligent piping, for these tanks any heating equipment is completely redundant. The other heating and cooling units can be designed smaller. Both are controlled via temperature sensors and ensure that the optimum operating temperature is maintained. Well-aimed conducting of the flow also renders the water make-up pump redundant. Finally the use of speed-controlled pumps ensures the required emulsion delivery.

* Technical contribution to the 51st Rolling Seminar - Processes, Rolled and Coated Products, October $28^{\text {th }}$ to $31^{\text {st }}, 2014$, Foz do Iguaçu, PR, Brazil. 


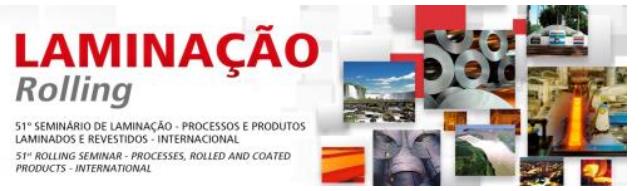

\subsection{Results}

Depending on the size of the plant, ECU requires less than half of the floor space of a conventional emulsion plant. Moreover, the compact design allows highly energysaving operation. The energy consumption is reduced up to 45 percent by using lost heat for heating up the base oil. Out of these approx. 35 percent is saved due to reduced pumping to deliver the demand and approx. 10 percent through utilizing of the waste heat. Downsizing the necessary auxiliary system, e.g. a water treatment plant, here also leads to reduction of the cost. Moreover, maintenance is cut down because the plant is made up of fewer components. In addition all units are easily accessible. All this cuts operation costs.

Compared to a conventional emulsion system, the ECU investment expenditures are nearly reduced by 20 percent. The modular structure in line with the considerably reduced piping expenditure shortens the final installation period and enables speedy commissioning. In fact assembly and commissioning time is cut down for more than 15 percent.

\section{TRC $^{\circledR}$ - THREAD AND TAIL-OUT ASSISTANT FOR FAST START OF ROLLING AND LOWER OFF-GAUGE LENGTHS}

\subsection{Initial Situation}

SMS Siemag introduced the rolling assistant system Total Roll Gap Control $\left(\mathrm{TRC}^{\circledR}\right)$ into the market as a part of the level 2 (Figure 10) to compensate certain disadvantages of discontinuous cold rolling mills versus continuous mills. The rolling assistant system increases process stability in rolling and improves the yield, especially during threading in and tailing out of the strip.

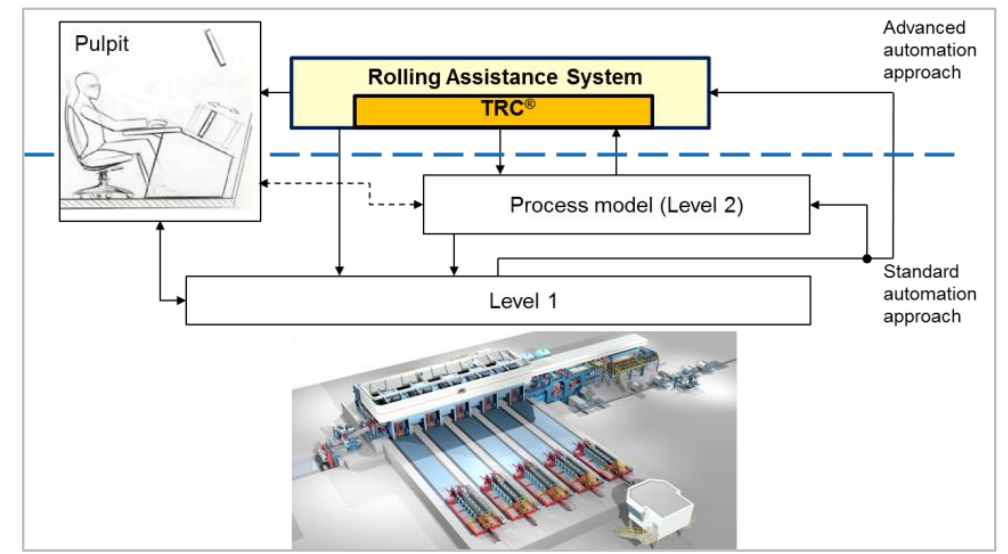

Figure 10: TRC ${ }^{\circledR}$ as part of the level 2 ensures a fast and save threading procedure in cold rolling mills

\subsection{Solution}

$\operatorname{TRC}^{\circledR}$ supports the threading and tail-out processes in such way that the strip can rolled down as early and as long as possible to the target gauge and intended quality. This achieves a reduction of off-gauge lengths at the strip head and tail ends.

\footnotetext{
* Technical contribution to the 51st Rolling Seminar - Processes, Rolled and Coated Products, October $28^{\text {th }}$ to $31^{\text {st }}, 2014$, Foz do Iguaçu, PR, Brazil.
} 


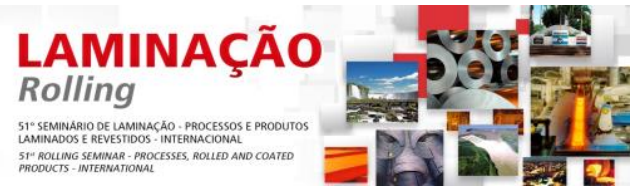

\subsection{Results}

$\operatorname{TRC}^{\circledR}$ was installed for the first time in the discontinuous tandem mill of Bilstein $\mathrm{GmbH}$ \& Co.KG as scope of modernization (Figure 11). Experience gained in operation showed that $\mathrm{TRC}^{\circledR}$ significantly accelerated the threading and tail-out processes and made them more reliable. The off-gauge lengths were reduced by approx. 50 percent. The annual savings of Bilstein, thanks to the $\mathrm{TRC}^{\circledR}$, averages up to 1 million $€$ per year. Meanwhile SMS Siemag also installed the system in an aluminum tandem cold mill.

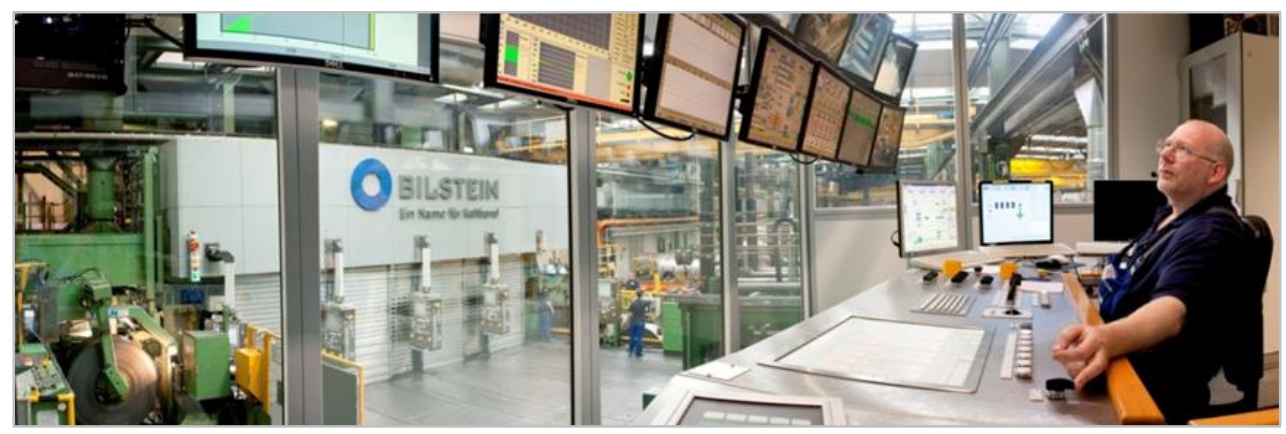

Figure 11: The $\mathrm{TRC}^{\circledR}$ rolling assistance system at Bilstein supports the TCM operator in fast and reliable strip threading and tailing-out with the result of significant yield increase

\section{ECO-MODE AND ENERGY ADVISOR CREATE THE REQUIRED TRANSPARENCY FOR OPERATING THE MILL AND THE PLANT EFFICIENTLY}

\subsection{Initial Situation}

In a cold rolling facility generally energy savings are limited. In the actual rolling process energy-savings only can be realized by further optimization of the emulsion used, at which process stability has to be guaranteed at any time. Process data allowing to control or tune the auxiliaries under energy saving aspects more efficiently, were hardly available.

\subsection{Solution}

SMS Siemag's new assistant ECO-Mode and monitoring system X-Pact ${ }^{\circledR}$ Energy Advisor make a substantial contribution to efficient and resource-saving operation of cold rolling mills (Figure 12).

* Technical contribution to the 51st Rolling Seminar - Processes, Rolled and Coated Products, October $28^{\text {th }}$ to $31^{\text {st }}, 2014$, Foz do Iguaçu, PR, Brazil. 
of Georgsmarienhütte $\mathrm{GmbH}$, points out the importance of key performance indicators in controlling energy efficiency, and especially their product and status dependencies. "For an effective energy management, it is necessary to connect energy data with the production as does the X-Pact ${ }^{B}$ Energy Advisor by SMS Siemag AG", says Laermann.

\section{CONCLUSIONS}

Beside the well-known and well-proven systems that characterize SMS Siemag's cold rolling mills, such as highly dynamic adjustment systems and CVC ${ }^{\circledR}$ plus, the new developments presented enable compact plant design without compromising performance and ensure profitable and ecological operation of the facility.

The technological examples are components of recent development effort for new plants but also for revamping of existing ones.

\section{REFERENCES}

1 Hundrieser J, Seifert O. Stahl und Eisen, 2009; 129 (7).

* Technical contribution to the 51st Rolling Seminar - Processes, Rolled and Coated Products, October $28^{\text {th }}$ to $31^{\text {st }}$, 2014, Foz do Iguaçu, PR, Brazil. 